\title{
Free-floating epithelial micro-tissue arrays: A low cost and versatile technique
}

\author{
P Flood $^{\mathrm{a}}$, L Alvarez $^{\mathrm{b}}$, and E G Reynaud ${ }^{\mathrm{c} *}$ \\ ${ }^{a}$ APC MIcrobiome Institute, University College Cork, Cork, Ireland \\ ${ }^{\mathrm{b}}$ Wellcome Trust Centre for Human Genetics, University of Oxford, Oxford, UK \\ ${ }^{\mathrm{c}}$ School of Biomolecular and Biomedical Science, University College Dublin, Dublin, Ireland \\ *Corresponding author e-mail: emmanuel.reynaud@ucd.ie
}

\section{Contact:}

Dr Emmanuel G. Reynaud

UCD Conway Institute

School of Biomolecular and Biomedical Science

University College Dublin

Belfield

Dublin 4

IRELAND

Tel: +353(0)1 7162260

E-mail: emmanuel.reynaud@ucd.ie 
Epithelial micro-tissue arrays

\begin{abstract}
Three dimensional (3D) tissue models are invaluable tools that can closely reflect the in vivo physiological environment. However, they are usually difficult to develop, have a low throughput and are often costly; limiting their utility to most laboratories. The recent availability of inexpensive additive manufacturing printers and open source 3D design software offers us the possibility to easily create affordable $3 \mathrm{D}$ cell culture platforms. To demonstrate this, we established a simple, inexpensive and robust method for producing arrays of freefloating epithelial micro-tissues. Using a combination of 3D Computer Aided Design and 3D printing, hydrogel micro-moulding and collagen cell encapsulation we engineered microenvironments that consistently direct the growth of micro-tissue arrays. We described the adaptability of this technique by testing several immortalized epithelial cell lines and by generating branching morphology and micron to millimetre scaled micro-tissues. We established by fluorescence and electron microscopy that micro-tissues are polarized, have cell type specific differentiated phenotypes and regain native in vivo tissue qualities. Finally, using Salmonella typhimurium we show micro-tissues display a more physiologically relevant infection response compared to other epithelial models. In summary, we have developed a robust and adaptable technique for producing arrays of epithelial micro-tissues. This in vitro model has the potential to be a valuable tool for studying epithelial cell and tissue function/architecture in a physiologically relevant context.
\end{abstract}




\section{INTRODUCTION}

Cell biology is moving towards the $3^{\text {rd }}$ dimension. Three dimensional (3D) cell culture better simulates in vivo conditions by providing cells with additional environmental factors; physiologically relevant substrates and a $3 \mathrm{D}$ tissue architecture ${ }^{1}$. It is now acknowledged that $3 \mathrm{D}$ cell cultures produce data that can be more predictive of the biology in vivo ${ }^{2}$. Functional epithelial micro-tissues are in particularly high demand for preclinical drug screening ${ }^{3}$, oncology studies ${ }^{4}$, basic research ${ }^{5}$ and host-pathogen interactions ${ }^{6}$. However, problems associated with increasing sample throughput are preventing the widespread implementation of those 3D approaches in cell Biology ${ }^{7,8}$.

Multicellular spheroids and microcarrier systems currently have the highest throughput 9,10 , but may be of limited physiological relevance. Scaffold based systems possess morphological and functional characteristics that are closer to in vivo tissue ${ }^{11,12}$. However, due to a number of technical difficulties scaffold techniques have much lower sample throughput compared to microcarrier and spheroid systems. Usually, the generation of samples is inconsistent and most protocols are difficult to scale up, expensive and labour intensive ${ }^{8,9}$.

Using microfabrication to control the encapsulation of cells in hydrogel scaffolds addresses many of these issues. Experimental timescales are short, the use of biomaterials is cost-effective and it can enable precise control over tissue size and shape in a scalable manner 13. Laminar flow extruders, PDMS/glass chips and 3D bio-printers are commonly used for microfabricating environments to direct hydrogel cell encapsulation.

Multiphase laminar flow triple/double orifice cylindrical extruder systems generate elongated fibres containing embedded cells ${ }^{14-17}$. Different cell populations can be selectively encapsulated in either the core or the outer wall of the fibres ${ }^{14,15}$.

Polydimethylsiloxane (PDMS) chips fabricated with micro-channels ${ }^{18}$, complex 3D topography ${ }^{19}$ or $2 \mathrm{D}$ arrays of nozzles ${ }^{20}$ can also be used to direct precise hydrogel cell encapsulation. These PDMS substrates are created using techniques such as photolithography ${ }^{18}$, laser engraving ${ }^{19}$, Computer Numerical Control (CNC) milling ${ }^{19}$ and deep reactive ionetching ${ }^{20}$. One particularly novel glass chip system has phaseguides to separate channels of hydrogel ${ }^{21}$, and uses a high resolution photo plotter to create the mask.

Finally, advanced 3D bio-printers can generate complex tissues by extruding hydrogel encapsulated cells in a highly controlled manner ${ }^{22}$. 
All the above technologies enable efficient and precise hydrogel encapsulation of cells. However, they require specialist or custom made equipment, they involve complicated, time consuming protocols and are often not cost effective.

In this study we propose a simple inexpensive technique for consistently generating arrays of free-floating epithelial micro-tissues utilizing microfabrication and hydrogel cell encapsulation. Using Computer Aided Design (CAD) and a standard 3D printer, we built customized cell culture devices for moulding multiple hydrogel tissue culture scaffolds. We adapted an established technique to micro-mould linear channels in parallel through these scaffolds ${ }^{23}$. The channels are then used to direct cell encapsulation. We quantitatively determined that the generation and development of micro-tissue arrays is consistent; and that micro-tissue growth is stable for up to 6 weeks. The systems versatility was demonstrated by testing multiple epithelial cell types (A549, MDCK-1 and Caco-2) and producing micro-tissues of different sizes and "branching" morphologies.

Using confocal microscopy, Light Sheet Fluorescence Microscopy (LSFM) Transmission Electron Microscopy (TEM) and histology, we characterized the epithelial micro-tissues extensively. Cells were polarized outward towards the media environment and had distinct apical/basolateral zones and asymmetrically localized sub-cellular structures. Micro-tissues also had a differentiated phenotype that was cell type dependent. Finally, using Salmonella typhimurium we conducted a comparative infection assay with $2 \mathrm{D}$ filter grown monolayers, and found that micro-tissues displayed lower levels of bacterial adhesion and invasion.

Our simple and adaptable approach increases sample throughput of 3D scaffold cultures. This well characterized in vitro model can be used to investigate epithelial cell function and architecture (infection, polarization), providing a physiologically meaningful context in the laboratory. 


\section{Materials and methods}

\subsection{D cell culture}

All cell lines were grown at $37{ }^{\circ} \mathrm{C}$ and $5 \% \mathrm{CO}_{2}$ in a humidified atmosphere. Cells were subcultured after they reached 80-90\% confluence using standard trypsinization protocols. For all experiments Madin Darby Canine Kidney-1 (MDCK-1) cells were maintained using Eagle's minimum Essential Medium (MEM) (Sigma-Aldrich®) containing 10\% v/v Foetal Bovine Serum (FBS), Caco-2 cells were maintained using MEM containing 20\% v/v FBS and A549 cells were maintained using F-12K media (Gibco®) containing 10\% v/v FBS. Media was supplemented with $100 \mathrm{UI} / \mathrm{ml}$ penicillin and $100 \mathrm{mg} / \mathrm{ml}$ streptomycin (Sigma-Aldrich ${ }^{\circledR}$ ) unless otherwise specified and $1 \%$ (v/v) L-glutamine (Gibco®).

\subsection{Design and fabrication of hydrogel moulding device}

The hydrogel moulding devices were designed using a freeware version of Google SketchUp (http://www.sketchup.com/download). Models were exported as an STL file using the SketchUp STL extension (STL file available in Electronic Supplementary Information). The files were imported into Cura 3D printer open source software (https://ultimaker.com/en/products/cura-software) and prepared for printing, after which they were converted to G-code files. From the G-code files the devices were printed using the Ultimaker 2 with PolyLactic Acid (PLA) as the build material. Once the print was completed a needle (gauge dependent on experiment) was used to manually bore holes through the guides designed into the device.

\subsection{Preparation of hydrogel moulding device for cell culture}

All plastic devices used for moulding the hydrogel scaffolds were cleaned and sterilized by a combination of sonication and several incubation/washing steps with $70 \%$ Industrial Methylated Spirits (IMS). Before use the device was washed $\geq 3$ times in Phosphate Buffered Saline (PBS). Appropriate gauge sterile needles were inserted through the openings created in the device. Using sterilized Parafilm one side of the device was sealed. Each moulding compartment was filled with a solution of $1.5 \%$ w/v type VII agarose (Sigma-Aldrich $®$ ) in deionized filtered $\mathrm{H}_{2} \mathrm{O}$ containing $10 \%$ w/v pen/strep (10,000 units penicillin and $10 \mathrm{mg}$ 
streptomycin per $\mathrm{ml}$ ). Once the agarose was polymerized the needles were extracted, leaving a linear channel through each of the hydrogel blocks.

\subsection{D cell culture}

Cells were trypsinized at $80-90 \%$ confluence. Complete media with $10 \%$ FBS was added after obtaining a homogenous cell suspension to deactivate the trypsin. The cell suspension was centrifuged at $450 \mathrm{x}$ g for $5 \mathrm{mins}$ at $37^{\circ} \mathrm{C}$, the supernatant was removed and cells were resuspended in neutral type I collagen solution (Sigma-Aldrich ${ }^{\circledR}$ C4243 - see manufacturer's instructions for details). 5.0-7.0 x 10 4 cells $/ 1 \mu$ of collagen was used for seeding as indicated. Collagen concentration was optimized for efficient micro-tissue formation dependent on cell type, $2 \mathrm{mg} / \mathrm{ml}$ (unless otherwise specified) for MDCK-1, $1.25 \mathrm{mg} / \mathrm{ml}$ for A549 and $1.5 \mathrm{mg} / \mathrm{ml}$ for Caco- 2 cells. The homogenized collagen/cell solution was then loaded into a $1 \mathrm{ml}$ syringe using an appropriate gauge Luer-lok connected needle. The needle was inserted through the openings of the moulding chamber and the solution was injected into the linear channels created in the agarose blocks. The Parafilm was removed, and the entire apparatus was placed into a cell culture dish. Media was then added and the apparatus was placed in an incubator at $37{ }^{\circ} \mathrm{C}$ and $5 \% \mathrm{CO}_{2}$. The micro-tissues were left to culture inside the agarose channels for up to 6 weeks, with a media change twice a week. In order to remove the micro-tissues the agarose blocks were pushed out of the moulding chamber using a sterile metal spatula into a cell culture dish containing media. The samples could then be removed from the agarose channel by pipetting, and transferred using the pipette to an Eppendorf tube for fixation (sample characterization) or a tissue culture well for infection assays.

\subsection{Branching micro-tissues}

Sets of needles with the same gauge were modified by cutting out half cylinder sections from the needle shaft using a precision drill equipped with a diamond saw attachment. The sections were cut half way through the needle shaft and were approximately the length of the needle diameter. Once complete the two needles can be interlocked to form a cross (orthogonal branching geometry). These needle sets were used to mould two channels linked by a + junction through an agarose scaffold. Once moulded the needles can be disconnected and extracted without damaging the channels. The channels are then seeded and cultured as per the nonbranching protocol above. 
Epithelial micro-tissue arrays

\subsection{Morphological measurements}

Datasets of micro-tissues were created at 5 time points during their development: 1 hour, 24 hours, 3 days, 5 days and 7 days post seeding. Images were acquired using a Leica M165FC stereomicroscope equipped with a Leica DFC490 CCD camera. The 8bit images were thresholded and an ellipse was auto-fitted to each micro-tissue to find the length of the major axis. All image processing was done using FIJI (http://fiji.sc).

\subsection{TEM}

Samples were first fixed in $2.5 \%$ glutaraldehyde in cell line specific media without serum (preheated to $37^{\circ} \mathrm{C}$ ) for 1 hour at room temperature. Samples were post fixed in $1 \%$ osmium tetroxide in Sørensen's phosphate buffer for 1 hour at room temperature. Subsequently, the specimens were dehydrated in a graded ethanol series $(30 \%, 50 \%, 70 \%, 90 \%$ and 100\%). Samples were transferred from $100 \%$ ethanol to acetone, and then to a 1:1 acetone/epoxy resin for 1 hour. To complete the resin infiltration samples were placed in $100 \%$ resin at $37{ }^{\circ} \mathrm{C}$ for 2 hours. Finally samples were embedded in resin and incubated at $60{ }^{\circ} \mathrm{C}$ for 24 hours until polymerization was complete. Ultrathin $(80 \mathrm{~nm})$ sections were obtained from regions of interest using a Leica EM UC6 ultramicrotome. These sections were collected on 200 mesh thin bar copper grids, stained with uranyl acetate $(20 \mathrm{~min})$ and lead citrate $(5 \mathrm{~min})$ and examined by TEM using a Tecnai $\mathrm{G}^{2} 12$ BioTWIN (FEI) with an accelerating voltage of 120 $\mathrm{kV}$.

\subsection{Tissue sections}

Samples were first fixed in $2.5 \%$ glutaraldehyde in cell line specific media without serum (preheated to $37^{\circ} \mathrm{C}$ ) for 1 hour at room temperature. Specimens were dehydrated in a graded ethanol series $(30 \%, 50 \%, 70 \%, 90 \%$ and 100\%). Samples were transferred from $100 \%$ ethanol to acetone, and then to a 1:1 acetone/epoxy resin for 1 hour. To complete the resin infiltration samples were placed in $100 \%$ resin at $37{ }^{\circ} \mathrm{C}$ for 2 hours. Finally samples were embedded in resin and incubated at $60{ }^{\circ} \mathrm{C}$ for 24 hours until polymerization was complete. $1 \mathrm{~mm}$ thick cross and longitudinal sections were taken from samples using a Leica EM UC6 ultramicrotome. The samples were stained with toluidine blue and mounted using Mowiol®. A Leica DMI6000 B 
inverted microscope equipped with a Leica DFC340 FX camera was used to acquire an overlapping grid of images that covered each tissue section using a 40X/1.25 objective. These grids were then stitched together to create the final high resolution images of the tissue sections using the pairwise stitching plug in for FIJI ${ }^{24}$.

\subsection{Fluorescence microscopy sample preparation}

Samples were washed 3 times using 0.25\% Tween 1X PBS between each step of processing. First, samples were fixed in $3 \%$ formaldehyde $1 \mathrm{X}$ PBS solution for 25 mins at room temperature. Samples were then quenched using a 30 mins incubation with $50 \mathrm{mM}$ Tris $1 \mathrm{X}$ PBS solution. Samples were permeabilized using 0.1\% Triton X-100 1X PBS solution for 20 mins. Samples were stained using $3 \mu \mathrm{g} / \mathrm{ml}$ Hoechst 33342 (Invitrogen $^{\mathrm{TM}}$ ) and $100 \mathrm{nM}$ rhodamine phalloidin (Cytoskeleton, Inc.) in 1X PBS for 30 mins. Immunohistochemistry samples were blocked using a 3\% FBS $0.25 \%$ tween 1 X PBS buffer for 60 mins. They were then incubated with primary antibody diluted in the blocking buffer at $4{ }^{\circ} \mathrm{C}$ over night using a sample rocker. The following antibodies and dilutions were used: anti-GM130 (BD Biosciences) 1:400, anti-ZO1 (Zymed) 1:200, anti-NHE3 (StressMarq) 1:200, anti- $\alpha / \beta$ tubulin (Cell Signaling) 1:200, anti-E-cad (BD Transduction Laboratories) 1:150 and anti-COPII (Bethyl Laboratories Inc.) 1:50. This was followed by incubation with the secondary antibody under the same conditions. The following secondary antibodies and dilutions were used: Alexa Fluor ${ }^{\circledR} 488$ 1:400, Alexa Fluor® 568 1:400 and Alexa Fluor® 647 1:200.

\subsection{LSFM}

For LSFM imaging a Lightsheet Z.1 was used with 10x/0.5 and 20x/1.0 detection optics combined with Zen software. The sample was embedded in a cylinder of a $0.5 \%-2 \%(\mathrm{w} / \mathrm{v})$ type VII low melting agarose gel held by a glass capillary. The sample is inserted from above into the PBS-filled chamber and the capillary can be translated along three axes and rotated around its centre. Processing of LSFM data was done using FIJI.

\subsection{Confocal microscopy}

An Olympus Fluoview FV1000 and Fv10-ASW 4.1 software was used for all imaging excluding the infection assay. Infection imaging was performed using a Zeiss LSM 700 with Zen software. Filter membranes were excised from inserts and slide mounted using Mowiol@. 


\subsection{Salmonella typhimurium infection assay}

Costar ${ }^{\circledR} 12 \mathrm{~mm}$ Transwell ${ }^{\circledR} 0.4 \mu \mathrm{m}$ pore polyester membrane inserts were prepared as per manufactures instructions and seeded with $2.5 \times 10^{4}$ MDCK- 1 cells per well. The Transwell ${ }^{\circledR}$ cells were cultured for one week, monolayers were confluent on the day of the experiment. MDCK-1 micro-tissues were prepared using 21 gauge needles and a $5 \times 10^{4}$ cells per $\mu 12$ $\mathrm{mg} / \mathrm{ml}$ suspension of collagen solution. Micro-tissues were cultured for four weeks prior to infection. 1 hour before the experiments monolayers and micro-tissues had a media change using 3\% FBS, 1\% (v/v) L-glutamine MEM without antibiotics. Micro-tissues were removed from their agarose channels and placed in ibidi $\mu$-slide 8 well imaging slides. Prior to this a 3D printed PLA block was inserted into each well in order to reduce the volume and maximize the tissue surface area in contact with bacterial cells (supplementary Figure 1). Salmonella typhimurium (ATCC 14028) frozen stock was inoculated in LB broth the day before the experiment and allowed to grow overnight. 3 hours before infection, the overnight Salmonella culture was used to inoculate DMEM with 3\% FBS and $1 \%(\mathrm{v} / \mathrm{v}) \mathrm{L}$-glutamine solution 1:20 vol/vol. After 3 hours growth, salmonella was used for infections at a final OD of 0.3 (600 $\mathrm{nm}$ ). The bacterial cells were labelled with 5(6)-TAMRA (Invitrogen ${ }^{\mathrm{TM}}$ ) using a previously established protocol ${ }^{25}$. Infections were initiated and allowed to progress for up to three hours in an incubator at $37{ }^{\circ} \mathrm{C} 5 \% \mathrm{CO}_{2}$. Filter grown monolayers and micro-tissues were incubated with the same total number of bacteria per sample ( $10^{7}$ cells). This corresponds to 15 bacteria per cell for the filter setting and 217 bacteria per surface cell for the micro-tissue. Infection was terminated by adding $37 \%$ formaldehyde directly to the culture vessels for a final $3.7 \%$ concentration. Samples were allowed to fix for $30 \mathrm{mins}$ in the incubator and then for 1 hour at room temperature, followed by several washes with 1X PBS. Samples were fixed at 90 and 180 mins post $S$. typhimurium infection, control samples without $S$. typhimurium were fixed at the start and end of the infection period following the same protocol ( $\mathrm{n}=1$ for all treatments). For quantitative analysis a Leica DMI6000 B inverted microscope equipped with a Leica DFC340 FX camera was used to acquire 25 field of views covering each sample using a Cy3 filter and 40X/1.25 objective. Manual counts of bacteria were conducted for each field of view and the average number of adherent bacteria per $1 \times 10^{5} \mu \mathrm{m}^{2}$ of sample is given $( \pm 1$ standard deviation). 


\section{Results and discussion}

\subsection{Device design and generation of free-floating epithelial micro-tissues}

Using 3D CAD and 3D printing; we constructed customized cell culture devices for moulding multiple hydrogel tissue culture scaffolds (Figure 1(a)). 3D printing DIY lab hardware is an emerging approach, and has already been used to produce medical implements ${ }^{26}$ and cell culture inserts ${ }^{27}$. The build material, PLA, is a plastic polymer that is fully biocompatible and remains mechanically stable in a long term culture environment ${ }^{28}$. The $3 \mathrm{D}$ model shown in Figure 1(a) has 12 moulding chambers [10 x $5 \times 4.5 \mathrm{~mm}$ ] each of which has top and bottom connecting compartments [5 x $2.5 \times 4.5 \mathrm{~mm}$ ], together forming a single channel unit. The number of chambers and dimensions of the device can be easily modified using the open source CAD software (supplementary Figure 2).

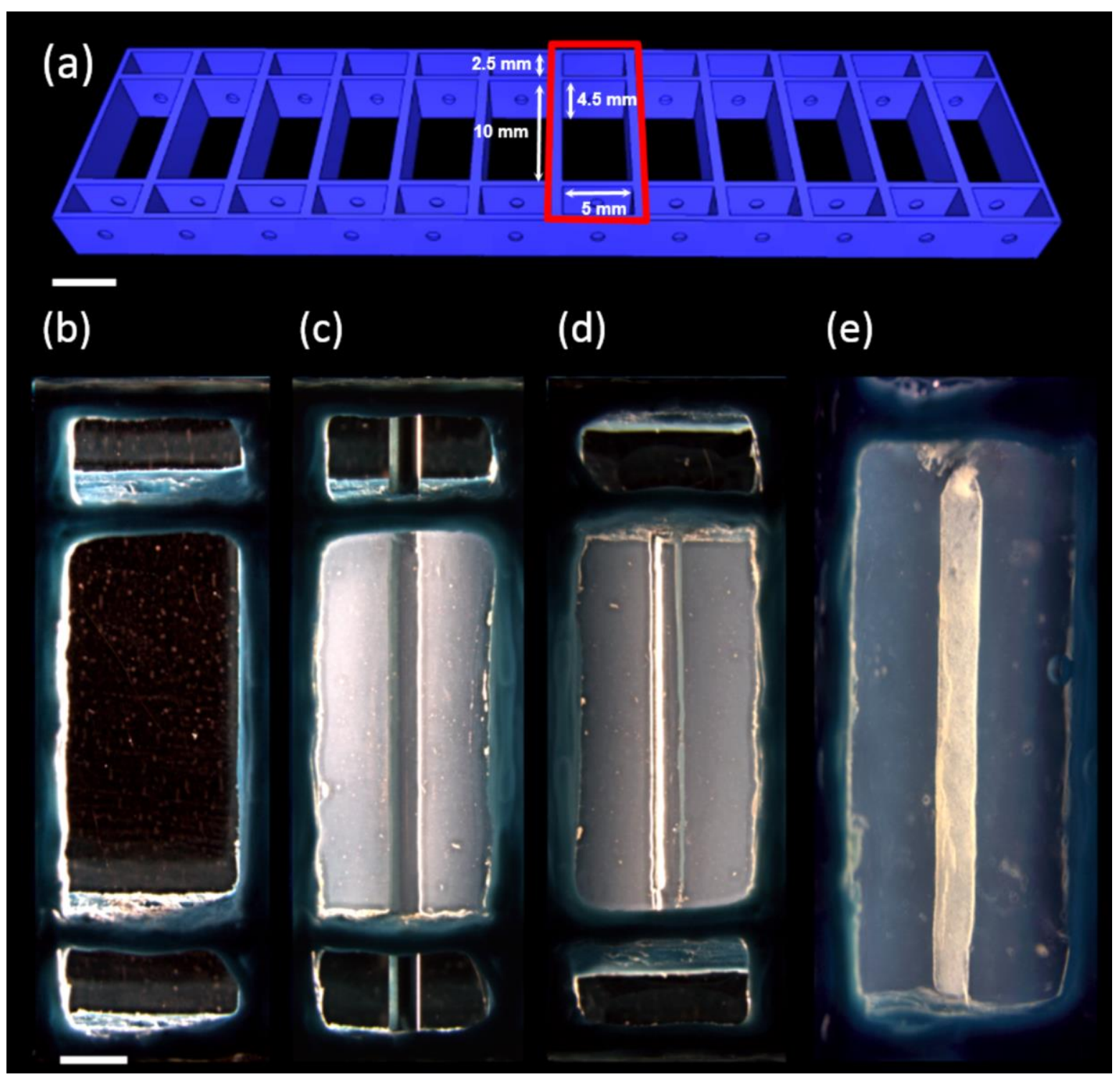

Figure 1. Set-up for micro-tissue generation. (a) The 3D model from Google SketchUp, with the internal dimensions of a moulding chamber and connecting compartment labelled, a single channel unit is 
highlighted in red. Scale: $5 \mathrm{~mm}$. (b) An individual moulding chamber, scale: $2 \mathrm{~mm}$. (c) A $21 \mathrm{G}$ needle is inserted, agarose is loaded into the chamber and allowed to polymerize. (d) The extracted needle leaves a linear channel. (e) Collagen/MDCK-1 cell mixture one hour after seeding, the collagen/cell construct is starting to recede from the agarose at of the sides of the channel.

Previous studies have demonstrated that using hypodermic needles it is possible to mould microscale channels through hydrogels ${ }^{29}$. We adapted this technique to micro-mould linear channels for cell encapsulation using our cell culture device, a collagen/cell solution is then injected into each channel (Figures 1(b)-(e)). The function of the two compartments either side of the moulding chamber is to collect excess collagen/cell solution during the injection process and provide an aqueous environment to prevent air bubbles from entering the channel.

The principle reason for choosing agarose to direct collagen cell encapsulation is it's biologically inertness. The formation of the micro-tissue relies on the principle that cells will aggregate if the adhesive forces between cells and the collagen are stronger than adhesion to the inert agarose. This concept is similar to the liquid over-lay technique for spheroid formation ${ }^{30}$. Hydrogels like agarose also possess good biocompatibility, are easy to process and readily allow for the diffusion of nutrients and cell products ${ }^{31}$. As diffusion is possible no specialized design features are needed for changing media, such as micro-posts for sample retention ${ }^{32}$. Finally, agarose has excellent optical qualities due to the low polymer concentration required to form a stable gel, this allows for direct observation of the micro-tissues (Figure 2).

One hour post seeding separate clusters of cells can still be distinguished inside the channel (Figure 2(a)). As time progresses the micro-tissue compacts and changes morphology (Figures 2(a)-(c)). After 1 week no significant changes are seen (Figures 2(c) and (d)). The development of micro-tissues was recorded over a week using 5 time points to quantify the reduction in major axis length (Figure 2(e)). After 24 hours the length of micro-tissues reduced by $31.5 \%[ \pm 4.87 \%]$, the largest change in size between time points recorded. The micro-tissues then steadily decreased in length over the sampling period until they were $52.8 \%[ \pm 4.1 \%]$ of their original length 1 week post seeding (Figure 2(e)). The micro-tissues stabilize after 1 week and the rate of compaction decreases significantly (Figure 2(d)). After 1 week in culture the average final length of micro-tissues was $4.94 \mathrm{~mm}[ \pm 0.56 \mathrm{~mm}]$. The micro-tissues are stable in culture for at least 6 weeks, this is advantageous as long term culture is known to produce more differentiated samples ${ }^{11}$. The data demonstrates that micro-tissue generation is consistent, and changes in micro-tissue size can be modelled with reasonable accuracy. This is important, as size and morphology should be homogenous when generating arrays of samples for screening and other applications ${ }^{7}$. 

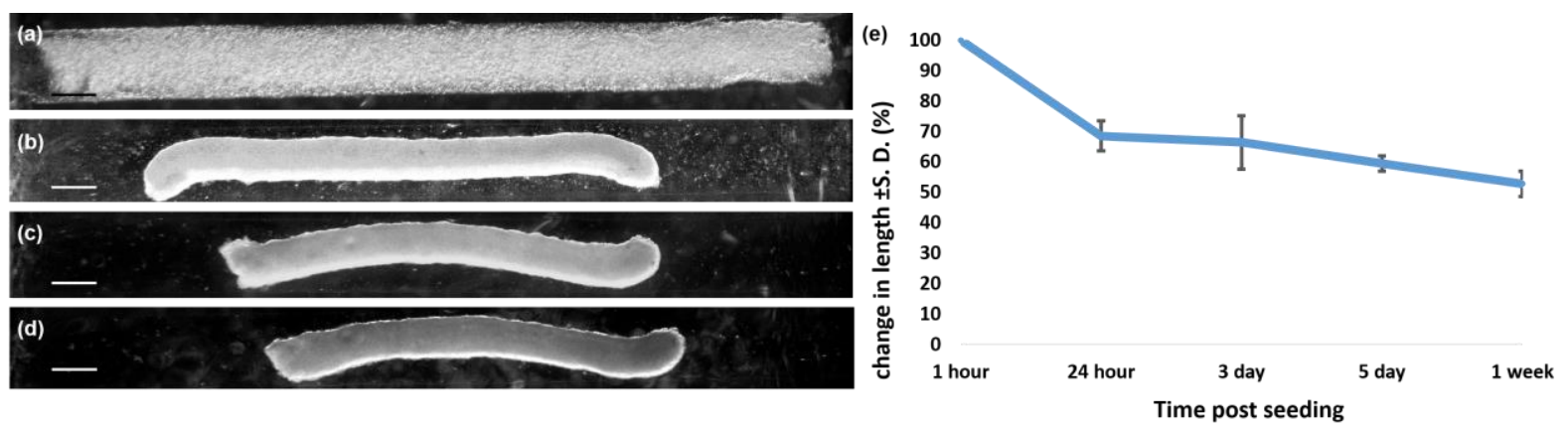

Figure 2. Tracking micro-tissue development. (a)-(d) Time series following a single micro-tissue over two weeks. (a) 1 hour. (b) 3 days. (c) 1 week. (d) 2 weeks. Scale (a)-(d): $500 \mu$ m. (e) Graph tracking changes in micro-tissue length over 1 week, the length of micro-tissues reduces by $47.2 \% \pm 4.1 \%$ over the sampling period. For this set of experiments channels were moulded using $21 \mathrm{G}$ needles and seeded with a $5 \times 10^{4}$ MDCK-1 cells per $\mu 1$ of $2.5 \mathrm{mg} / \mathrm{ml}$ type I collagen solution (Data is pooled from two independent experiments, $\mathrm{n}=10$ and 8 respectively, error bars $= \pm 1$ standard deviation).

The system was designed to produce free-floating arrays of micro-tissues, which have a number of advantages: 1) Free floating micro-tissues are easy to access and manipulate. To generate certain 3D epithelial cell cultures cells must be embedded inside an Extracellular Matrix (ECM) scaffold (organoids, epithelial cysts) ${ }^{5,11}$. These cultures cannot be accessed directly without mechanically disrupting the surrounding matrix (which also alters the architectural and morphological characteristics of the cultures). 2) Free-floating epithelial micro-tissues are ideal for microscopic analysis. They can be manipulated and imaged from all directions, allowing for multiview acquisition. Additionally, there is no thick heterogeneous scaffold that must be imaged through, resulting in less optical aberrations and light scattering. 3) Free-floating collagen gels increase levels of epithelial cell differentiation compared to fixed gels as the cells are able to contract and remodel the matrix ${ }^{33}$.

Patterned PDMS substrates ${ }^{18-20,34}$, co-axial multiphase laminar flow cylindrical extruder systems ${ }^{14-17}$, phaseguides ${ }^{21}$ and 3D bio-printing ${ }^{22}$ have all been used to direct hydrogel cell encapsulation using channels. However, the cost and technical complexity of these systems prevents non specialized laboratories from using them on a regular basis. Additionally, the multiphase laminar flow extruder systems are generally not suitable for producing homogenous arrays of samples and choice of biomaterials is limited. Our set-up has a low entry cost level, and its open source nature should enable laboratories to easily adapt the system to their specific needs. A basic 3D printer that can print at a standard sufficient for most non-industrial needs can be purchased for a few hundred euro (http://printrbot.com). Both PLA and agarose are cost effective materials, and the use of collagen in the protocol is highly efficient $(\approx 300 \mu$ l to seed twelve $21 \mathrm{G}$ channels). With open source software the user can easily 

3 4

modify the CAD files and has control over the number of moulding chambers, the length of the micro-tissues and the dimensions of the hydrogel scaffolds.

\subsection{Branching epithelial micro-tissues and scalability}

In order to demonstrate the versatility of the technique we generated different sized and branching micro-tissues (Figure 3). By using different gauge needles it is possible to control the width of the hydrogel channel and thus the diameter of the micro-tissues generated (Figures 3(c) and (d) and supplementary Figure 3).
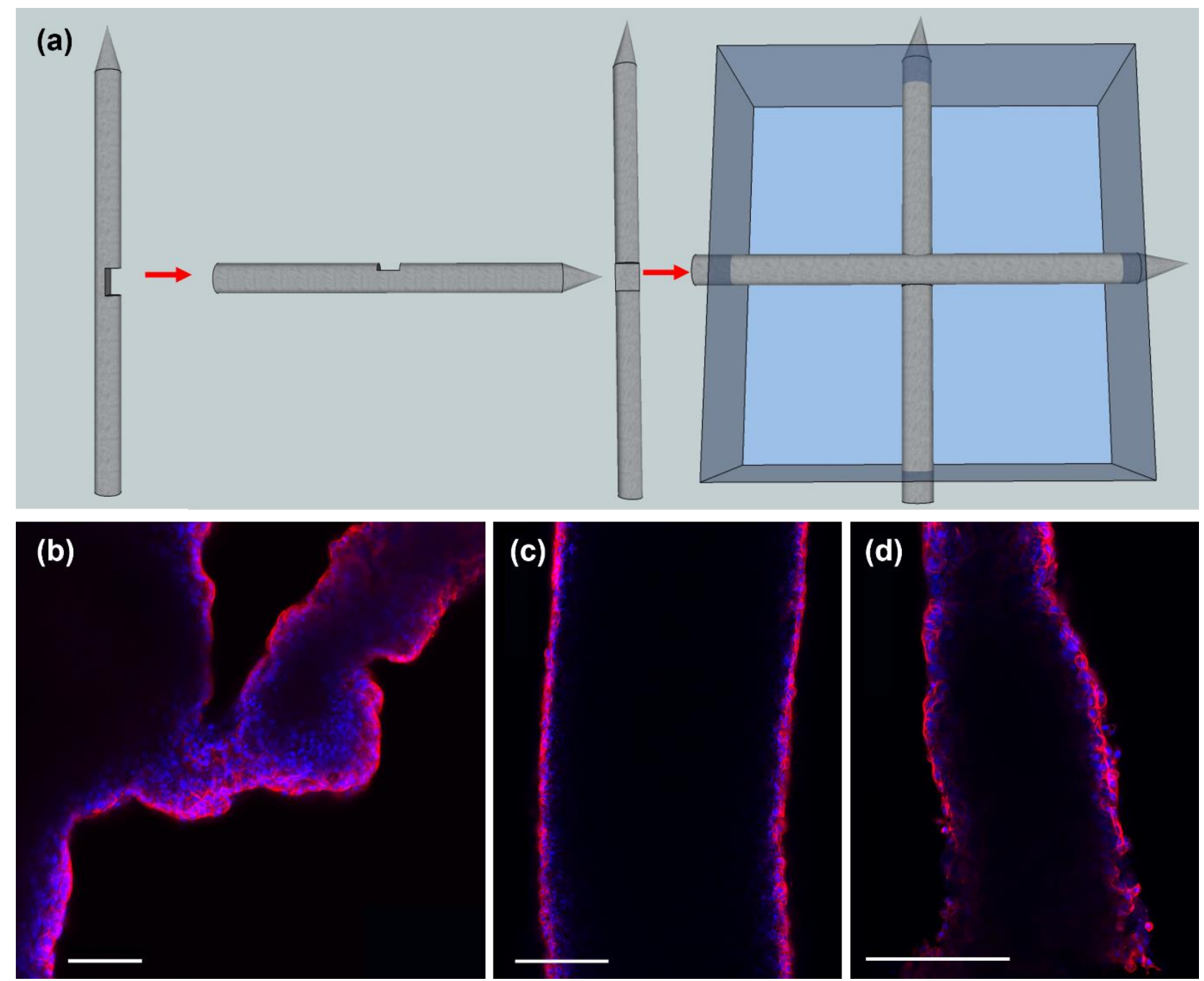

Figure 3. Micro-tissue generation protocol is versatile. (a) Diagram illustrating needle modification and assembly for branching micro-tissue generation. (b) A "branching" micro-tissue, tissue formation is directed by agarose channels linked by a + junction, the confocal image shows one side of the tissue junction. (c) Confocal image acquired from the centre of a micro-tissue generated using a $21 \mathrm{G}$ needle $[0.8192 \mathrm{~mm}]$. (d) Confocal image acquired from the centre of a micro-tissue generated using a $27 \mathrm{G}$ needle $[0.4128 \mathrm{~mm}]$. Note the difference in micro-tissue diameter between (c) and (d). Labels: Phalloidin (Red, Actin) and Hoechst (Blue, Nucleus). Scales: $100 \mu \mathrm{m}$. 
This allows us to generate epithelial micro-tissues with scalable sizes which can be tailored to the needs of an experiment (e.g. smaller micro-tissues to allow for faster in toto imaging, larger micro-tissues for producing increased volumes of epithelial excretions). By adjusting the procedure we moulded hydrogel channels that contain a junction. A set of needles was modified allowing them to be connected and detached easily (Figure 3(a)). These needles are inserted orthogonally into an adapted moulding chamber and connected (Figure 3(a)). Once the agarose has polymerized the needles are detached and extracted avoiding damage to the channels. The resulting hydrogel junction directs the growth of micro-tissues with a branching morphology (Figure 3(b)).

It has been demonstrated that tissue architecture can modify the physiological functionality of cells ${ }^{19}$. Tissue geometry can also alter the spatial distribution of mechanical stress, disproportionately affecting cells depending on their position within the tissue ${ }^{35}$. Our branching micro-tissues could be used to study the behaviour and organization of cells in complex geometries that occur in vivo. Other techniques to produce branching tissues via encapsulation utilize a combination of topographic cell capture substrates and bulk hydrogel encapsulation (InVERT) ${ }^{19}$, and a modified stereolithographic apparatus ${ }^{36}$. These techniques have impressive spatial resolution and can produce morphologically advanced tissues, however they also require specialist equipment and labour intensive protocols.

\subsection{Epithelial micro-tissue characterization}

These micro-tissues were intended as an in vitro model system to study epithelial cell and tissue biology in a physiologically relevant context. Therefore it was important to characterize the micro-tissues extensively and to determine if their characteristics correspond to well differentiated tissue. We used LSFM, TEM, histology and confocal microscopy to comprehensively investigate the phenotype and tissue organization of the micro-tissues.

\subsection{Epithelial micro-tissue organization}

An LSFM Z-stack covering the entire volume of a section of a micro-tissue indicated a tubular tissue morphology (Figure 4 and supplementary Movie 1), which is directed by the cylindrically shaped hydrogel channel. We confirmed that by two weeks post seeding the cells formed a confluent monolayer around the periphery of the micro-tissue (Figure 4). The central section of the tissue has a lower cell density and lacks any clear cellular organization (Figures 
2

3
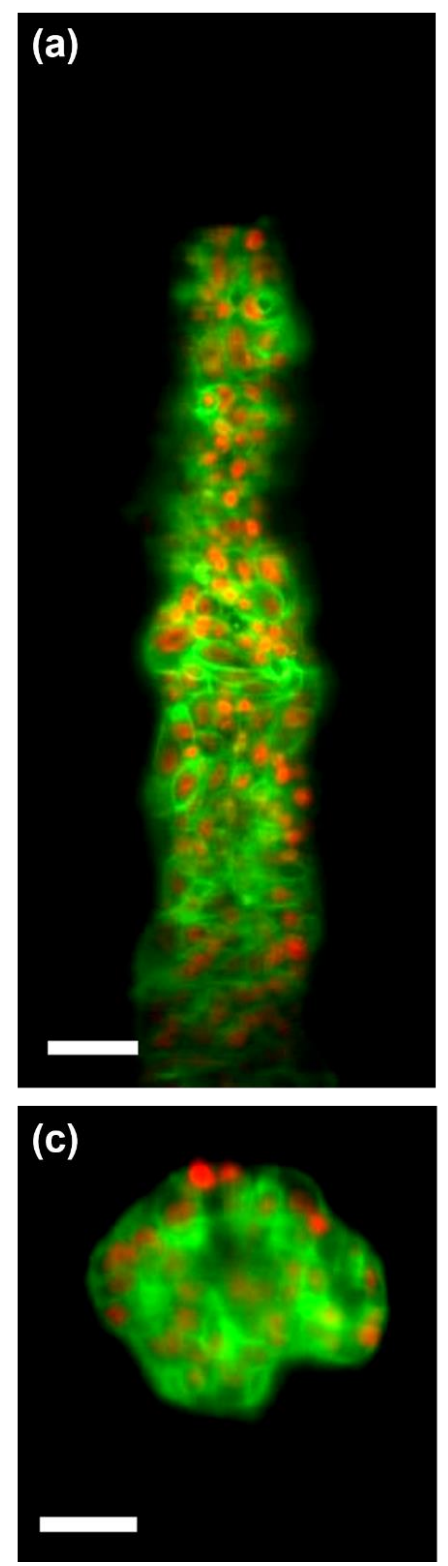

\section{(b)}
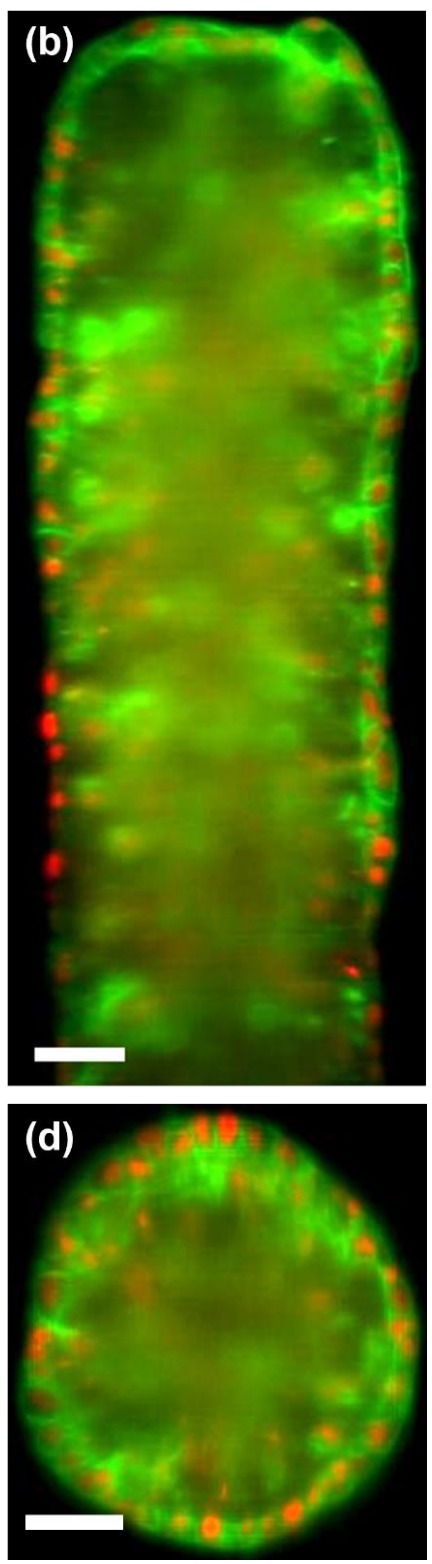

Figure 4. Micro-tissue tissue organization: Representative images from an LSFM dataset [Objective: 20x] of a 2 week old MDCK-1 epithelial micro-tissue. Cells form a confluent monolayer around the periphery of the tissue, the internal section of the tissue has a lower cell density. (a) Longitudinal optical section of micro-tissue surface. (b) Longitudinal optical section from the centre of the micro-tissue. (c) Optical transverse section from the terminal end of the micro-tissue. (d) Optical cross section from centre of the micro-tissue dataset. Labels: Phalloidin (Green, Actin) and Hoechst (Red, Nucleus). Scales: $25 \mu \mathrm{m}$. 
Epithelial micro-tissue arrays

\subsection{Epithelial micro-tissue phenotype is cell line dependent}

In order to demonstrate that our technique is applicable to various tissue types we tested three immortalized cell lines, each from a different epithelial organ; A549 (lung), MDCK-1 (kidney) and Caco-2 (colon). Cell lines were chosen over primary cultures for their consistency, ease of use and affordability. Additionally, we assessed the capacity of this culture system to promote cell type dependent differentiation. We used a combination of histology and TEM to examine the internal/external tissue, cell and subcellular morphology of micro-tissues (Figures 5 and 6). The cells were polarized outward towards the media and had clear apical and basolateral membrane surfaces for all micro-tissues (Figure 5). All tissues had an interior network of loosely arranged collagen, but cells appeared not to directly interact with the ECM at their basal membranes (supplementary Figure 4).

Epithelial micro-tissues had distinct phenotypes that were cell type dependent. MDCK1 epithelial micro-tissues have a tightly associated simple cuboidal epithelium, which is typical of the distal tubule, their tissue of origin. The tissue has a dense core of necrotic cells (Figure 5). Necrotic cores are known to develop in cell spheroids due to limited diffusion of oxygen and nutrients ${ }^{37}$. This usually occurs following a gradient with layers of cells becoming less active from the periphery of the spheroid inwards, until reaching the hypoxic necrotic core ${ }^{38}$. In our MDCK micro-tissues, there is a single monolayer of viable cells directly followed by necrotic tissue (Figure 5). It's possible that when the internal cells are prevented from forming a polarized phenotype with three distinct cell surfaces they become apoptotic, which commonly occurs in vivo ${ }^{5}$. MDCK-1 micro-tissue cells had distinct ultrastructural characteristics; a dense network of well-developed mitochondria localized to the perinuclear region, short sparse luminal microvilli, large domed apical surfaces and extensive basolateral membrane interdigitations (Figures 6(a) and (b)). These features are all characteristic of in vivo distal convoluted tubule cells ${ }^{39,40}$. MDCK-1 cells express antigens specific to the convoluted section of the canine distal tubule, which confirm that they were isolated from this particular tissue ${ }^{41}$. This structural data (in conjunction with the physiologically correct localization of the NHE3 sodium co-transporter to the apical membrane, see Figure 7(b)) would indicate that MDCK-1 micro-tissues partially regain their in vivo functionality. Other 3D polarized MDCK-1 systems lack most of these morphological features ${ }^{42-44}$, suggesting that our technique produces more physiologically relevant tissues. 


\section{Tissue cross section}

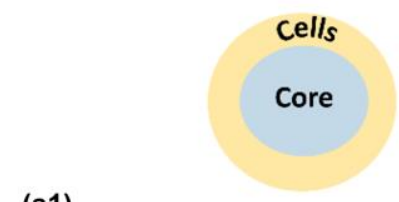

(a1)
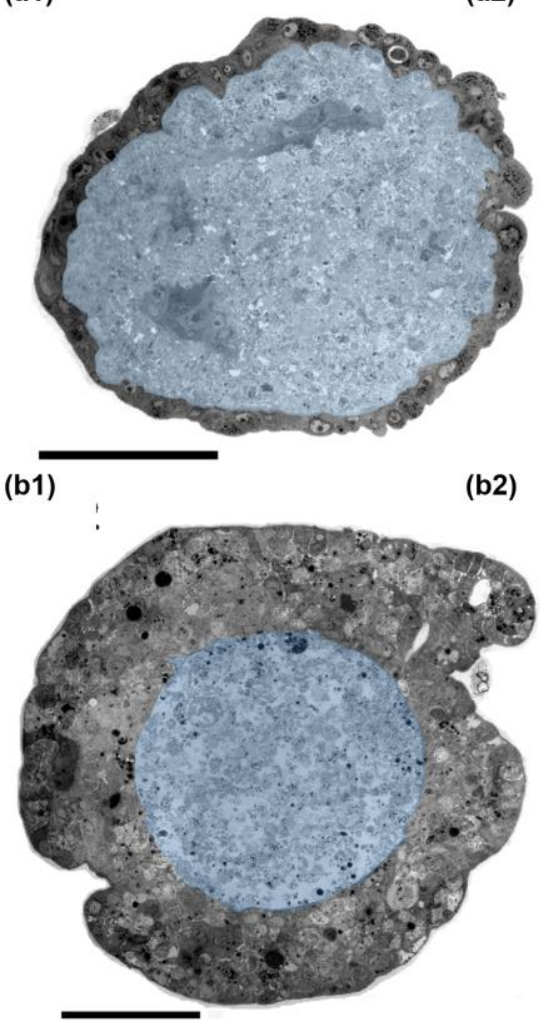

(c1)

(c2)

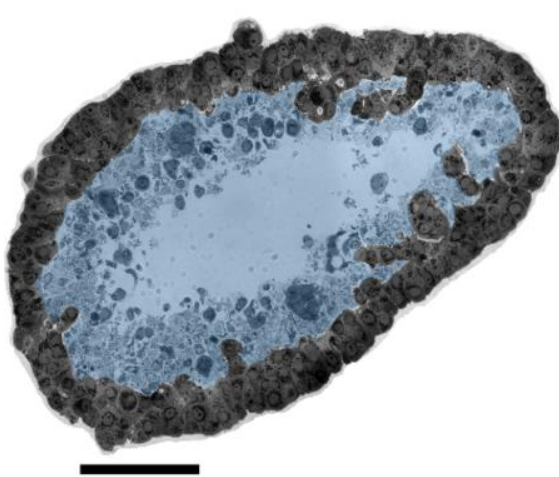

(a2)
Tissue longitudinal section
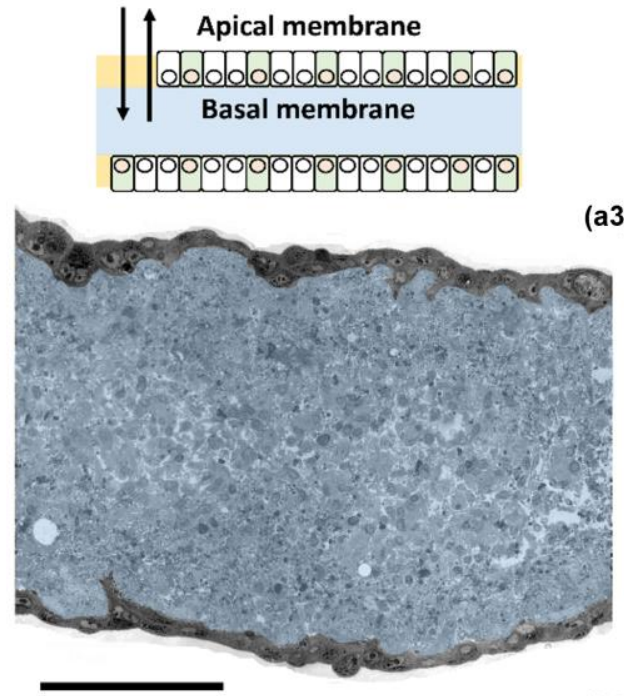

(b3)
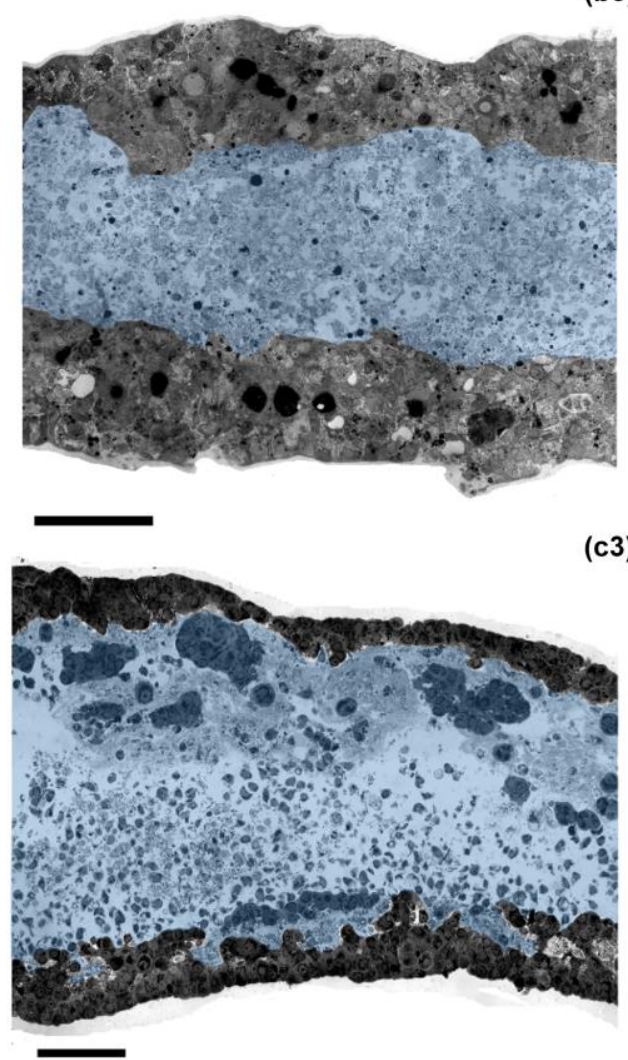

TEM: cell section

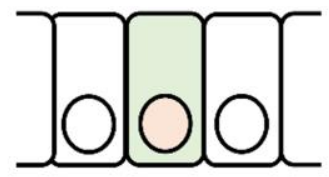

(a3)
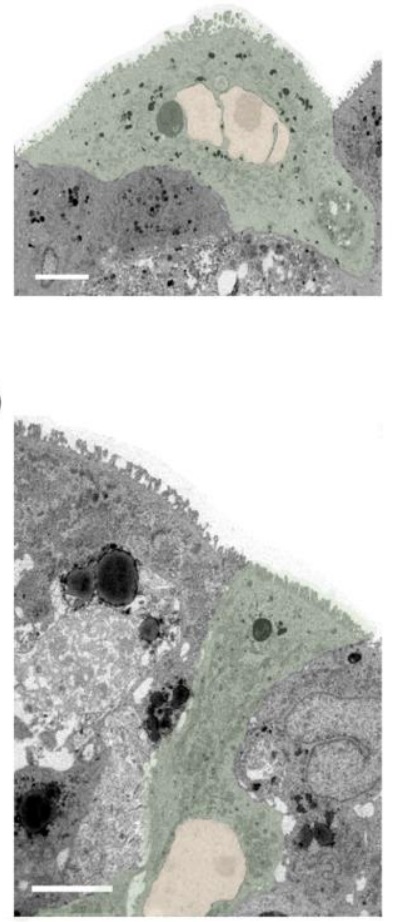

(c3)

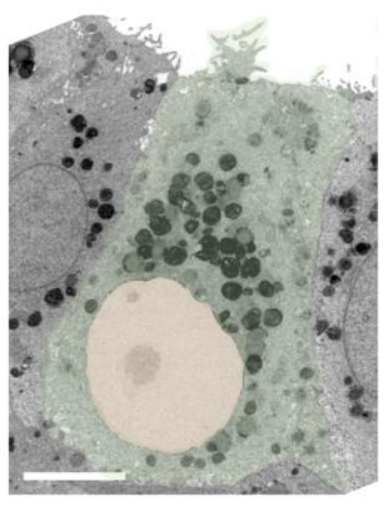

Figure 5. Micro-tissue histology sections display cell type dependent morphology at a tissue/cellular level. All samples were fixed after 4-6 weeks in culture. (a1) MDCK-1 cross section. (a2) MDCK-1 longitudinal section, a simple cuboidal epithelium. (a3) MDCK-1 TEM, cells have a distinctly large apical membrane. (b1) Caco-2 cross section. (b2) Caco-2 longitudinal section, the epithelium is stratified. (b3) Caco-2 TEM, highlighted cell has a tall columnar phenotype, while others Caco-2 cells are cuboidal (See Figure 6(b1)). (c1) A549 cross section. (c2) A549 longitudinal section, tissue resembles a pseudostratified ciliated columnar epithelium. (c3) A549 TEM, cells are columnar and have an extensive network of apical secretory vesicles. Tissue section scales: $100 \mu \mathrm{m}$, TEM scales: $5 \mu \mathrm{m}$. 
The Caco-2 epithelial micro-tissues are stratified and over $100 \mu \mathrm{m}$ thick at some sections of the tissue. The core of the Caco-2 tissue contained much less cell debris compared to the MDCK-1 micro-tissues (Figure 5). The epithelium contains a heterogeneous mix of cell morphologies; some are columnar and thin while others have a compact cuboidal shape (Figures 5 and 6(b1)). There was evidence of extensive mucous production throughout the tissue. Indicating the entire tissue is healthy and metabolically active. Some granules were $>20$ $\mu \mathrm{m}$ in size, and others had a very distinctive morphology (Figures 5 and 6(b1) and (b3)). Increased levels of mucous production has been previously reported in $3 \mathrm{D}$ Caco- 2 cultures ${ }^{3}$.

The exterior cell layer of the Caco-2 micro-tissues had several enterocyte characteristics, such as an exceptionally well developed brush border with a thick glycocalyx layer and microvilli almost 2,000 nm in length (Figure 6(b2)). Polarized Caco-2 cells are known to resemble enterocytes, but they usually grow as a simple monolayer. 3D cell cultures incorporating polarized Caco-2 monolayers are used to test intestinal paracellular drug absorption ${ }^{45}$ and as disease models ${ }^{46}$. However, as the Caco- 2 micro-tissues are stratified their use as a model of the intestine may be limited. Caco-2 cells were originally isolated from a colorectal carcinoma, this tissue has an important secretory function and at some sections is stratified (rectal canal). This unusual combination of characteristics from different tissue types is not unexpected considering the Caco- 2 cell line was isolated from an adenocarcinoma.

A549 micro-tissues resemble a pseudostratified ciliated columnar epithelium, a tissue type found in the upper respiratory tract (Figure 5). These tissues are the most viable, with very little evidence of necrotic cells or cell debris. The cells have a wider columnar morphology when compared to Caco-2 cells (Figure 5). A549 micro-tissue cells contained a large volume of secretory vesicles, consisting of mucus granules and well developed lamellar bodies (Figure 6). Increased secretion of MUC1 and MUC5A mucoglycoprotein has been reported in 3D A549 cultures ${ }^{47}$, and A549 cells are known to produce lamellar bodies ${ }^{48}$. A549's were originally isolated from a basal alveolar adenocarcinoma and are widely used as a model of type II alveolar cells ${ }^{48}$, a small cuboidal cell responsible for producing pulmonary surfactant through the secretion of lamellar granules ${ }^{49}$. The production of surfactant and a cuboidal shape has previously been described in A549 3D culture ${ }^{50}$. However, A549 micro-tissue cells were columnar and had well developed cilia (Figure 5). After reviewing the literature we found that morphologically the cells more closely resemble primary human airway epithelia cells cultured using the air liquid interface technique ${ }^{51}$. These cells, isolated from the trachea and bronchi, also have a pseudostratified ciliated epithelial phenotype. 

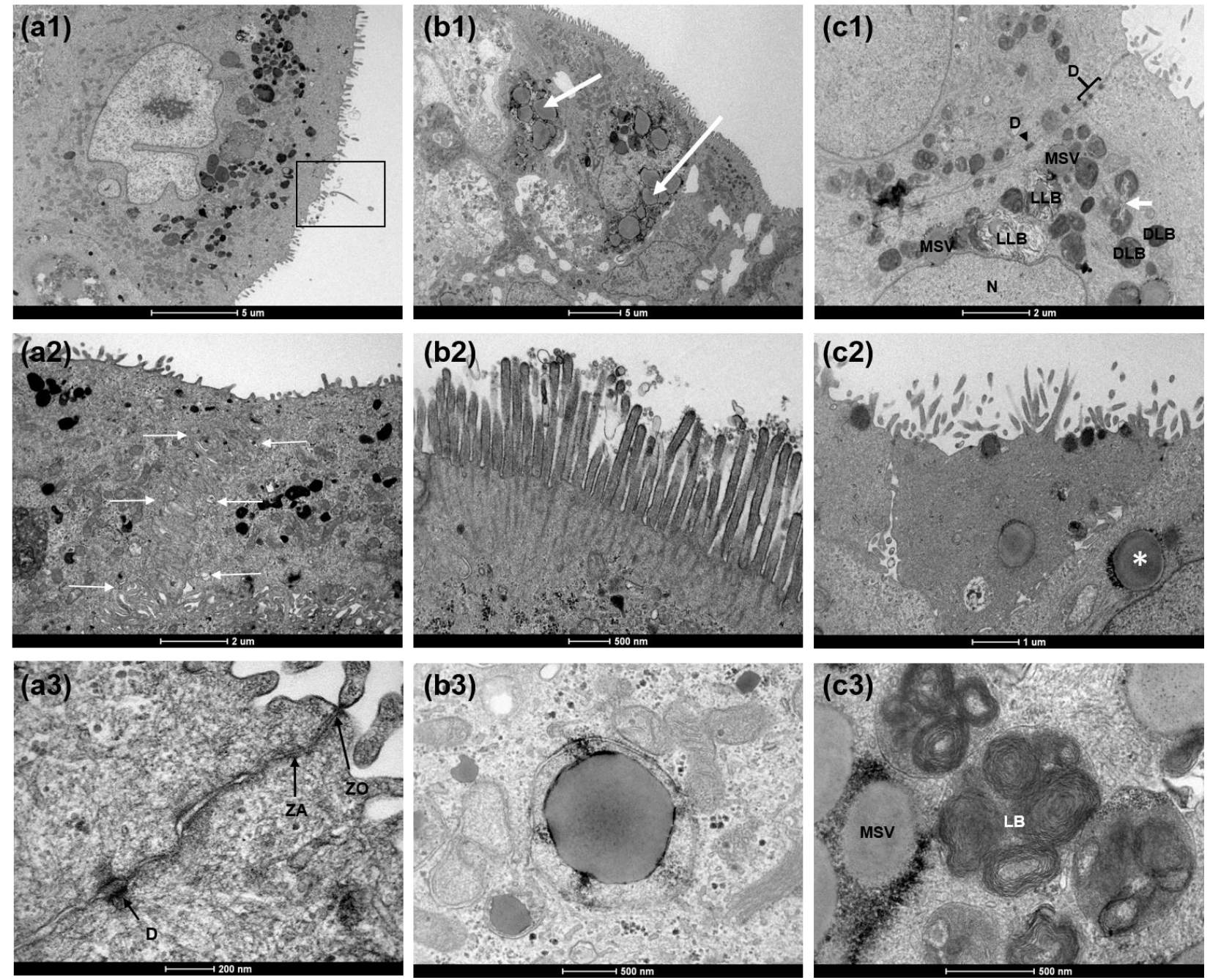

Figure 6. Micro-tissues display cell type dependent morphology at a subcellular level. All samples were fixed after 4-6 weeks in culture. (a1) MDCK-1 Cell with primary cilium highlighted, extensive vesicle traffic on apical side of the nucleus and dense network of mitochondria at basal end. (a2) Arrows highlight membrane interdigitations between two adjacent MDCK-1 cells, note the relatively undeveloped microvilli. (a3) Full junctional complex of MDCK-1 cell, consisting of Zona Occludens (ZO), Zona Adherens (ZA) and Desmosome (D). (b1) Caco-2 cells containing multiple large mucus granules ( $>1 \mu \mathrm{m}$ in diameter) indicated by arrows, these cells have a cuboidal morphology unlike the columnar cell highlighted in Figure 5. (b2) Highly developed brush border of a Caco-2 cell, glycocalyx can be seen on the tips of microvilli and between them; actin web below the border is easily visible. (b3) Distinct stage of secretory granule maturation in Caco-2 cell. (c1) Population of secretory organelles in A549 cell, consisting of Loose Lamellar Bodies (LLB), Dense Lamellar Bodies (DLB) and Mucus Secretory Vesicles (MSV). Several desmosomes (D) are seen along the plasma membrane of the two adjacent cells. White arrow indicates fusion event between two lamellar bodies. (c2) Vesicles fusing with the apical membrane of an A549 cell, vesicle marked with * has a partial "crown" covering its membrane. Note the well-developed microvilli. (c3) High magnification of A549 Mucus Secretory Vesicle (MSV) and Lamellar Body (LB). 
Epithelial micro-tissue arrays

\subsection{MDCK-1 micro-tissues as a model for polarization}

MDCK-1 filter grown monolayers are the standard model for research on epithelial polarity ${ }^{52-}$ ${ }^{54}$. We investigated if MDCK-1 micro-tissues could be used as an alternative in vitro system for studying polarization. Using confocal microscopy we examined the MDCK-1 micro-tissue polarized phenotype in greater detail. In conjunction with the TEM data we determined that micro-tissues had an extensively polarized cytoarchitecture, with distinct apical/basolateral domains and asymmetrically distributed sub-cellular structures and proteins (Figures 6 and 7).
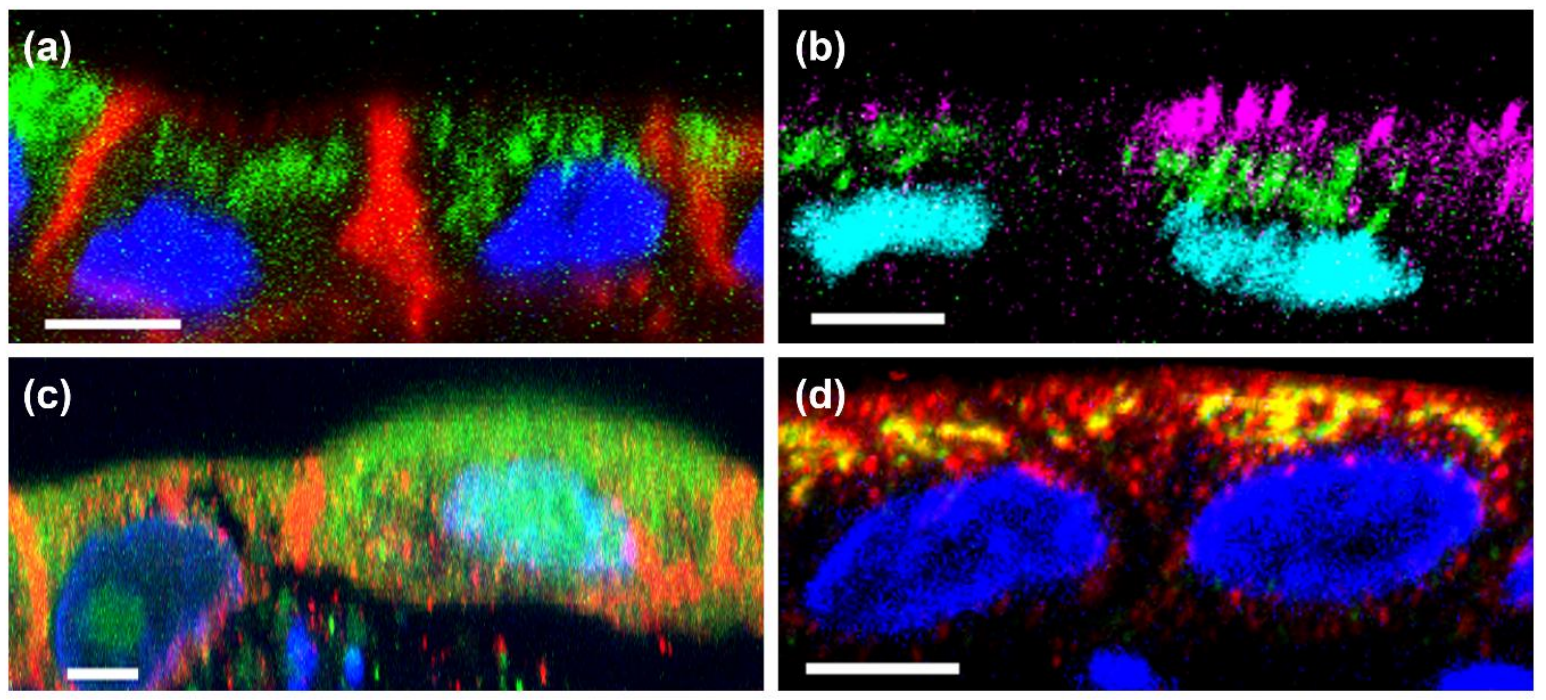

Figure 7. MDCK-1 micro-tissue cells have distinct apical/basolateral zones and asymmetrically localized subcellular structures. All samples were fixed after 4 weeks in culture. Each image is a Y-Z projection through $1.65 \mu \mathrm{m}$ of an immunostained MDCK-1 micro-tissue. The top of the image is apical and bottom is basal for all images. (a) Phalloidin (Red, Actin), anti-GM130 (Green, Golgi apparatus) and Hoechst (Blue, Nucleus). (b) AntiGM130 (Green, Golgi apparatus), Hoechst (cyan, nucleus) and anti-NHE3 (Pink, Sodium-hydrogen exchanger 3). (c) Anti-E-cad (Red; E-cadherin), anti- $\alpha / \beta$ tubulin (Green, Microtubules) and Hoechst (Blue; Nucleus). (d) Anti-COPII (Red, COPII), anti-GM130 (Green, Golgi apparatus), anti-COP II and anti-GM130 co-localization (Yellow, COPII and Golgi) and Hoechst (Blue, Nucleus). Z-stacks were acquired using a confocal microscope and a 60x objective, an increment of $0.2 \mu \mathrm{m}$ was used between slices. Scales: $5 \mu \mathrm{m}$.

Micro-tissues displayed the following subcellular markers typical of polarized epithelial cells:

1) Bundles of actin were observed at the apical surface of the cells (Figure 7(a)), which are required to support the microvilli enriched apical membrane ${ }^{5}$. 2) The Golgi apparatus was condensed and positioned between the apical membrane and nucleus, which was located in the basal region of the cell (Figures 7(a)-(c)) ${ }^{54}$. 3) Functionally localized NHE3 (sodiumhydrogen exchanger) membrane protein (Figure 7(b)). NHE3 is involved in maintaining the balance of salt present in the kidney nephron and localizes to the apical membrane in vivo ${ }^{55}$. 4) Strong E-cadherin signal along the lateral membrane (Figure 7(c)). E-cadherin is a key protein in establishing the epithelial phenotype and creating tightly adhering monolayers ${ }^{56} .5$ ). A dense tubulin network was present in the apical portion of the cell above the nucleus (Figure 


\subsection{Salmonella typhimurium Infection assay}

There is an urgency to better comprehend host-pathogen interactions in vivo due to increasing numbers of bacterial antibiotic resistant strains worldwide ${ }^{60}$. The 2D monolayer is a standard model for infection and is routinely used for the evaluation of bacterial pathogenicity ${ }^{61}$. Unfortunately, 2D monolayer systems do not recapitulate in vivo host-pathogen interaction accurately ${ }^{62}$. Alternatively, filter membrane systems can be used, and elicit more physiologically relevant behaviour from host and microbe cells compared to monolayers ${ }^{63}$. However, it is now recognized that well differentiated 3D culture systems mimic the in vivo response to infection most accurately ${ }^{6,11,62}$. The $3 \mathrm{D}$ cultures in this study, in contrast to $2 \mathrm{D}$ cultures, can for example secret mucus more efficiently, which acts as the natural protective barrier of epithelial cells in vivo. A recent publication also highlighted the plasticity of bacterial 

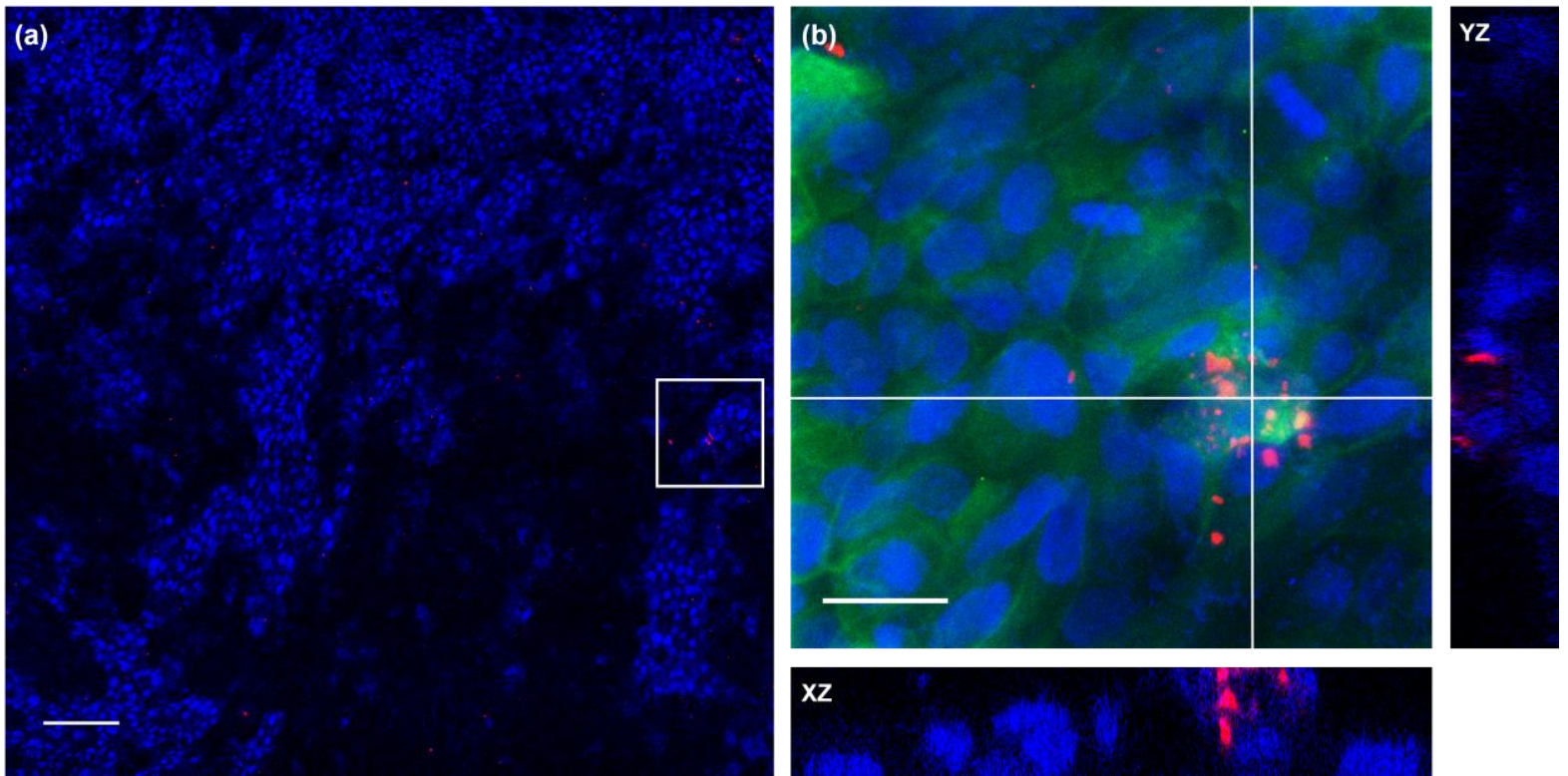

Figure 8. Confocal images of 180 mins post infection MDCK-1 filter membrane monolayer. (a) $1321 \times 1321 \mu \mathrm{m}$ confocal tile scan using a 60x/1.4 objective, labelling: TAMRA Salmonella (Red), and Hoechst (Blue). Multiple bacterial cells can be seen adhering to the monolayer. Scale: $100 \mu \mathrm{m}$. (b) MIP of $18 \mu \mathrm{m}$ Z-stack (60x) acquired at area highlighted in (a) and associated orthogonal views (XZ and $\mathrm{YZ}$ ). The position of the orthogonal slices is indicated by the white lines, labelling: Phalloidin (green). The group of cells in the bottom right of the image have multiple infections; orthogonal views indicate that the bacteria have invaded host cells. Scale: $20 \mu \mathrm{m}$.

The filter grown monolayer had 33.85 adherent bacteria per $1 \times 10^{5} \mu \mathrm{m}^{2}[ \pm 20.05] 180 \mathrm{mins}$ post infection. Adherent bacteria can be seen distributed across the sampled region of the monolayer (Figure 8). Where a group of bacterial cells was concentrated invasion of the monolayer can be seen (Figure 8 (b)). There is also an alteration to the organization of the actin cytoskeleton at this site of infection not seen in the control (Figure 8(b) and supplementary 


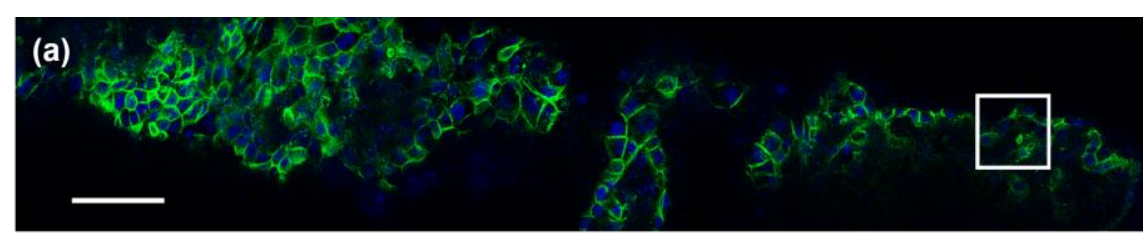

Figure 5). This has been previously observed, and is associated with Salmonella endocytosis 65.

For epithelial micro-tissue infections the volume of the wells was reduced by $74 \%$ using a 3D printed PLA block (PLA is biocompatible and non-toxic to bacterial cells ${ }^{66}$ ) (Supplementary Figure 1). This was done to increase the probability of contact between pathogens and host cells. Epithelial micro-tissues had 0.625 adherent bacteria per $1 \times 10^{5} \mu \mathrm{m}^{2}$ [ \pm 1.25$] 180$ mins post infection, 54 fold less than the filter grown monolayer (confocal data from the 90 mins time point also indicated that greater numbers of bacterial cells adhered to the filter membrane monolayer compared to the micro-tissue (Supplementary Figure 6)).
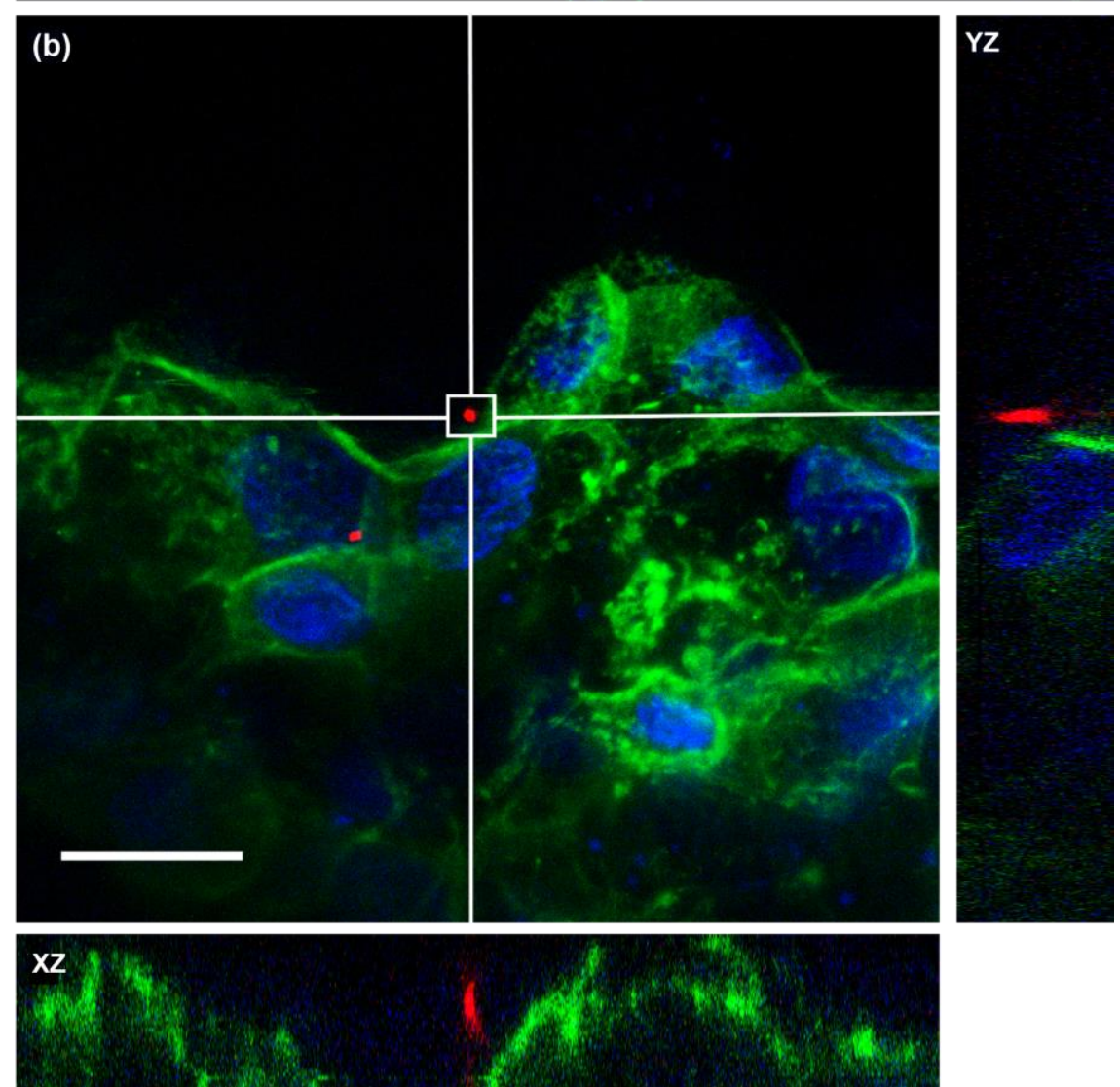

Figure 9. Representative confocal images from 180 mins post infection epithelial micro-tissue (for complete confocal data sets of micro-tissues see supplementary Figure 6). (a) 1219 × $203 \mu \mathrm{m}$ longitudinal confocal tile scan using a 60x/1.4 objective, labelling: Phalloidin (green), TAMRA Salmonella (red) and Hoechst (blue). Only one infection is visible, located inside the white box. Scale: $100 \mu \mathrm{m}$. (b) MIP of $18 \mu \mathrm{m} \mathrm{Z}$-stack (60x) acquired at area highlighted in (a) and associated orthogonal views (XZ and YZ). The position of the orthogonal slices is indicated by the white lines. The Z-stack reveals that there are actually two infections. However, the orthogonal views show that bacteria are 
adhered to the cell surface and have not invaded the cell or affected cellular integrity/ morphology (data not shown for second cell). Scale: $20 \mu \mathrm{m}$.

Confocal Z-stacks revealed that bacterial cells were adhering to the surface of the micro-tissue and had not breached the epithelial outer membrane (Figure 9(b)). Overall, no Salmonella were found internalized in the micro-tissues. The infected micro-tissue showed no significant changes in morphology and didn't display signs of epithelial barrier disruption compared to the control (Figure 9 and Supplementary Figure 7).

Lower invasion of 3D cell cultures compared to monolayers by Salmonella typhimurium has been reported previously ${ }^{67,68}$. It has been proposed that the lower levels of invasion are due to the in vivo like differentiation of $3 \mathrm{D}$ cell cultures. It's thought that factors other than intracellular invasion such as the secretion of bacterial effector proteins might play a more significant role during in vivo infection ${ }^{68}$. This suggests that our tissue model is a more physiologically relevant testbed for infection studies.

There are two commonly used systems to produce free-floating 3D cell cultures that can mimic the in vivo infection response and are suitable for imaging. These are 3D cell aggregates produced with the rotating wall vessel ${ }^{6,47}$, and intestinal organoids generated from adult stem cells ${ }^{11,69}$. These techniques have key disadvantages compared to our micro-tissue array platform. 3D aggregates lack the tissue complexity of scaffold models and samples are produced in a highly heterogeneous manner ${ }^{6}$. Intestinal stem cells must be embedded in Matrigel ${ }^{\circledR}$ in order to proliferate, limiting access to the organoid during growth ${ }^{11}$. The organoid lumen is also internalized, therefore bacterial cells must be microinjected inside the tissue to gain access to the apical membrane ${ }^{11}$. As they are polarized outward the apical membrane of our epithelial micro-tissues is available for application of bacteria or other reagents.

\section{Conclusion}

We have developed a simple and robust technique for consistently generating arrays of freefloating epithelial micro-tissues. This technique utilizes open source software, affordable 3D printing technology and commonly available lab consumables. We demonstrated that it is adaptable and scalable by generating micro-tissues of different morphologies, size and cell type. We have shown by quantitative measurements that the growth and development of the tissues can be modelled and that they can be produced consistently. Using various microscopic 
techniques the micro-tissues were characterised extensively. Micro-tissues had cell type specific differentiated phenotypes and regained some of their native in vivo tissue qualities. We determined that MDCK-1 micro-tissues have a well polarized cytoarchitecture, with distinct apical/basolateral domains and asymmetrically distributed sub-cellular structures. Finally, we conducted an infection assay using S. typhimurium and found that micro-tissues were resistant to infection compared to filter grown monolayers. We believe we have demonstrated that our micro-tissues are an effective in vitro model for studying epithelial processes such as infection and polarization in a physiologically relevant context.

\section{Acknowledgments}

The authors would like to thank Professor Martin Steer for his help editing the manuscript, and the UCD Conway Imaging Core for assistance with the electron microscopy included in the study. Dr Luis Alvarez acknowledges support from the European Cooperation in Science and Technology (COST) Action BM1203/EU-ROS and funding from the National Children's Research Centre (grant: K/12/1). 
Epithelial micro-tissue arrays

\section{References}

1. L. G. Griffith and M. A. Swartz, Nature Reviews Molecular Cell Biology, 2006, 7, 211224.

2. F. Pampaloni, E. G. Reynaud, and E. H. Stelzer, Nature reviews Molecular cell biology, 2007, 8, 839-845.

3. Z. Li, H. Sun, J. Zhang, H. Zhang, F. Meng, and Z. Cui, PloS one, 2013, 8, e72612.

4. L. Speroni, G. S. Whitt, J. Xylas, K. P. Quinn, A. Jondeau-Cabaton, C. Barnes, I. Georgakoudi, C. Sonnenschein, and A. M. Soto, Tissue Engineering, 2013.

5. L. E. O Brien, M. M. P. Zegers, and K. E. Mostov, Nature Reviews Molecular Cell Biology, 2002, 3, 531-537.

6. J. Barrila, A. L. Radtke, A. Crabbé, S. F. Sarker, M. M. Herbst-Kralovetz, C. M. Ott, and C. A. Nickerson, Nature Reviews Microbiology, 2010, 8, 791-801.

7. S. Breslin and L. O’Driscoll, Drug discovery today, 2013, 18, 240-249.

8. J. Gormley, Drug Discovery World, 2010, Summer 2010, 25-41.

9. B. A. Justice, N. A. Badr, and R. A. Felder, Drug Discov. Today, 2009, 14, 102-7.

10. C. R. Thoma, S. Stroebel, N. Rösch, B. Calpe, W. Krek, and J. M. Kelm, Journal of Biomolecular Screening, 2013, 1087057113499071.

11. J. L. Forbester, D. Goulding, L. Vallier, N. Hannan, C. Hale, D. Pickard, S. Mukhopadhyay, and G. Dougan, Infection and immunity, 2015, 83, 2926-2934.

12. M. M. Choe, A. A. Tomei, and M. A. Swartz, Nature protocols, 2006, 1, 357-362.

13. A. Kang, J. Park, J. Ju, G. S. Jeong, and S.-H. Lee, Biomaterials, 2014, 35, 2651-2663.

14. M. Hu, M. Kurisawa, R. Deng, C.-M. Teo, A. Schumacher, Y.-X. Thong, L. Wang, K. M. Schumacher, and J. Y. Ying, Biomaterials, 2009, 30, 3523-3531.

15. S. Sakai, Y. Liu, E. J. Mah, and M. Taya, Biofabrication, 2013, 5, 015012.

16. Y. Zhang, Y. Yu, A. Akkouch, A. Dababneh, F. Dolati, and I. T. Ozbolat, Biomaterials science, 2015, 3, 134-143.

17. T. Takei, N. Kishihara, S. Sakai, and K. Kawakami, Biochemical engineering journal, 2010, 49, 143-147.

18. X. Liu, Q. Wang, J. Qin, and B. Lin, Lab on a Chip, 2009, 9, 1200-1205. 
19. K. Stevens, M. Ungrin, R. Schwartz, S. Ng, B. Carvalho, K. Christine, R. Chaturvedi, C. Li, P. Zandstra, C. Chen, and others, Nature communications, 2013, 4, 1847.

20. S. Sugiura, T. Oda, Y. Aoyagi, M. Satake, N. Ohkohchi, and M. Nakajima, Lab on a Chip, 2008, 8, 1255-1257.

21. S. J. Trietsch, G. D. Israëls, J. Joore, T. Hankemeier, and P. Vulto, Lab on a chip, 2013, 13, 3548-3554.

22. M. Stanton, J. Samitier, and S. Sánchez, Lab on a Chip, 2015, 15, 3111-3115.

23. T. Takei, S. Sakai, T. Ono, H. Ijima, and K. Kawakami, Biotechnology and bioengineering, 2006, 95, 1-7.

24. S. Preibisch, S. Saalfeld, and P. Tomancak, Bioinformatics, 2009, 25, 1463-1465.

25. N. Corcionivoschi, L. A. Alvarez, T. H. Sharp, M. Strengert, A. Alemka, J. Mantell, P. Verkade, U. G. Knaus, and B. Bourke, Cell host $\backslash \&$ microbe, 2012, 12, 47-59.

26. J. Y. Wong, Aerospace Medicine and Human Performance, 2015, 86, 830-834.

27. C. Shen, Q. Meng, and G. Zhang, Biofabrication, 2015, 7, 015003.

28. D. H. Rosenzweig, E. Carelli, T. Steffen, P. Jarzem, and L. Haglund, International journal of molecular sciences, 2015, 16, 15118-15135.

29. T. Takei, S. Sakai, T. Yokonuma, H. Ijima, and K. Kawakami, Biotechnology Progress, 2007, 23, 182-186.

30. J. Friedrich, C. Seidel, R. Ebner, and L. A. Kunz-Schughart, Nature protocols, 2009, 4, 309-324.

31. A. S. Hoffman, Advanced drug delivery reviews, 2012, 64, 18-23.

32. S. H. Au, M. D. Chamberlain, S. Mahesh, M. V. Sefton, and A. R. Wheeler, Lab on a Chip, 2014, 14, 3290-3299.

33. M. A. Wozniak and P. J. Keely, Biological procedures online, 2005, 7, 144-161.

34. S. Raghavan, C. M. Nelson, J. D. Baranski, E. Lim, and C. S. Chen, Tissue Engineering Part A, 2010, 16, 2255-2263.

35. N. Gjorevski and C. M. Nelson, Biophys. J., 2012, 103, 152-62.

36. V. Chan, P. Zorlutuna, J. H. Jeong, H. Kong, and R. Bashir, Lab on a Chip, 2010, 10, 2062-2070.

37. K. Groebe and W. Mueller-Klieser, International Journal of Radiation Oncology* Biology* Physics, 1996, 34, 395-401. 
38. H. Page, P. Flood, and E. G. Reynaud, Cell and Tissue Research, 2012, 1-9.

39. R. F. Reilly and D. H. Ellison, Physiological Reviews, 2000, 80, 277-313.

40. B. A. Stanton, D. Biemesderfer, J. B. Wade, and G. Giebisch, Kidney Int, 1981, 19, 3648.

41. D. A. Herzlinger, T. G. Easton, and G. K. Ojakian, The Journal of cell biology, 1982, 93, 269-277.

42. A. L. Pollack, G. Apodaca, and K. E. Mostov, American Journal of Physiology-Cell Physiology, 2004, 286, C482-C494.

43. E. Reales, M. Bernabé-Rubio, J. Casares-Arias, C. Rentero, J. Fernández-Barrera, L. Rangel, I. Correas, C. Enrich, G. Andrés, and M. A. Alonso, J Cell Sci, 2015, 128, 22612270 .

44. P. H. Jakob, J. Kehrer, P. Flood, C. Wiegel, U. Haselmann, M. Meissner, E. H. Stelzer, and E. G. Reynaud, Cytotechnology, 2016, 1-13.

45. M. B. Esch, J. H. Sung, J. Yang, C. Yu, J. Yu, J. C. March, and M. L. Shuler, Biomedical microdevices, 2012, 14, 895-906.

46. F. Leonard, H. Ali, E.-M. Collnot, B. J. Crielaard, T. Lammers, G. Storm, and C.-M. Lehr, ALTEX, 2012, 29, 275-85.

47. A. Carterson, K. H. zu Bentrup, C. Ott, M. Clarke, D. Pierson, C. Vanderburg, K. Buchanan, C. Nickerson, and M. Schurr, Infection and immunity, 2005, 73, 1129-1140.

48. M. Lieber, G. Todaro, B. Smith, A. Szakal, and W. Nelson-Rees, International Journal of Cancer, 1976, 17, 62-70.

49. D. Wang, D. L. Haviland, A. R. Burns, E. Zsigmond, and R. A. Wetsel, Proceedings of the National Academy of Sciences, 2007, 104, 4449-4454.

50. A. D. Lehmann, N. Daum, M. Bur, C.-M. Lehr, P. Gehr, and B. M. Rothen-Rutishauser, European Journal of Pharmaceutics and Biopharmaceutics, 2011, 77, 398-406.

51. R. W. Walters, P. Freimuth, T. O. Moninger, I. Ganske, J. Zabner, and M. J. Welsh, Cell, 2002, 110, 789-799.

52. M. Cereijido, E. Robbins, W. Dolan, C. Rotunno, and D. Sabatini, The Journal of cell biology, 1978, 853-880.

53. Y. Wakabayashi, J. Chua, J. M. Larkin, J. Lippincott-Schwartz, and I. M. Arias, Histochemistry and cell biology, 2007, 127, 463-472.

54. R. Bacallao, C. Antony, C. Dotti, E. Karsenti, E. Stelzer, and K. Simons, The Journal of cell biology, 1989, 109, 2817-2832. 
55. D. Biemesderfer, J. Pizzonia, A. Abu-Alfa, M. Exner, R. Reilly, P. Igarashi, and P. S. Aronson, American Journal of Physiology-Renal Physiology, 1993, 265, F736-F742.

56. E. Rodriguez-Boulan and I. G. Macara, Nature reviews Molecular cell biology, 2014, 15, $225-242$.

57. I. Mellman and W. J. Nelson, Nature reviews Molecular cell biology, 2008, 9, 833-845.

58. K. Shin, V. C. Fogg, and B. Margolis, Annu. Rev. Cell Dev. Biol., 2006, 22, 207-235.

59. E. Wang, P. S. Brown, B. Aroeti, S. J. Chapin, K. E. Mostov, and K. W. Dunn, Traffic, 2000, 1, 480-493.

60. W. H. Organization and others, Antimicrobial resistance: global report on surveillance, World Health Organization, 2014.

61. J. E. Galan and R. Curtiss, Proceedings of the National Academy of Sciences, 1989, 86, 6383-6387.

62. A. L. Radtke, J. W. Wilson, S. Sarker, and C. A. Nickerson, PLoS One, 2010, 5, e15750e15750.

63. B. B. Finlay, B. Gumbiner, and S. Falkow, The Journal of cell biology, 1988, 107, 221230.

64. A. Schmidt, K. Kochanowski, S. Vedelaar, E. Ahrné, B. Volkmer, L. Callipo, K. Knoops, M. Bauer, R. Aebersold, and M. Heinemann, Nature biotechnology, 2016, 34, 104-110.

65. B. Finlay, S. Ruschkowski, and S. Dedhar, Journal of Cell Science, 1991, 99, 283-296.

66. D. Campoccia, L. Visai, F. Renò, I. Cangini, M. Rizzi, A. Poggi, L. Montanaro, L. Rimondini, and C. R. Arciola, Journal of Biomedical Materials Research Part A, 2015, 103, 1447-1458.

67. K. H. zu Bentrup, R. Ramamurthy, C. M. Ott, K. Emami, M. Nelman-Gonzalez, J. W. Wilson, E. G. Richter, T. J. Goodwin, J. S. Alexander, D. L. Pierson, and others, Microbes and infection, 2006, 8, 1813-1825.

68. C. A. Nickerson, T. J. Goodwin, J. Terlonge, C. M. Ott, K. L. Buchanan, W. C. Uicker, K. Emami, C. L. LeBlanc, R. Ramamurthy, M. S. Clarke, and others, Infection and immunity, 2001, 69, 7106-7120.

69. Y.-G. Zhang, S. Wu, Y. Xia, and J. Sun, Physiological reports, 2014, 2, e12147. 